\title{
EPIDEMIOLOGY OF PHARMACOLOGICAL TREATMENT OF MULTIPLE SCLEROSIS IN CROATIA
}

\author{
Sanja Tomasović ${ }^{1,2}$, Jelena Košćak Lukač ${ }^{1}$, Josip Sremec ${ }^{1}$, Nataša Klepac ${ }^{3}$, \\ Pero Draganic ${ }^{4} \&$ Ivan Bielen ${ }^{1,2}$ \\ ${ }^{I}$ Department of Neurology, University Hospital "Sveti Duh", Zagreb, Croatia \\ ${ }^{2}$ Medical School Josip Juraj Strossmayer University of Osijek, Osijek, Croatia \\ ${ }^{3}$ Department of Neurology, University Hospital Centre Zagreb, Medical School University of Zagreb, Zagreb, Croatia \\ ${ }^{4}$ HALMED, Agency for Medicinal Products and Medical Devices of Croatia, Ksaverska Road 4, Zagreb, Croatia
}

received: 16.10.2018;

revised: 26.2.2019;

accepted: 21.3.2019

\section{SUMMARY}

Treatment of multiple sclerosis has been a dynamic field lately, with many new and emerging treatment options. In this study, we investigate the use of disease modifying therapies (DMTs) for multiple sclerosis in Croatia. The data on DMT use was provided by the Agency for Medicinal Products and Medical Devices of Croatia (HALMED). The data from 2005 to 2016 was available. Consumption of DMTs (in DDD/1000/day) has been increasing by 9\% annually on average since 2005. In the same period, the annual cost for those drugs has been increasing by 14.6\% annually on average. The consumption of IFN-beta 1-a has been increasing by a much steeper rate than IFN-beta 1-b. Until 2010 the consumption of glatiramer acetate has been negligible, with a steep increase between 2011 and 2014, and a steady rate of consumption since. Recently, several new DMTs became available, namely dimethyl fumarate, teriflunomide and fingolimod. Natalizumab became available after 2010, and its consumption has been growing steadily, but its consumption figures are exceeded by alemtuzumab. New DMTs are not as readily available in Croatia as they are in some countries. However, there is a continuous increase in the number of prescriptions, along with growing costs in pharmacological treatment of multiple sclerosis, and this can be expected to become even more pronounced in the following years, due to the abundance of new therapeutic options that are steadily becoming available.

Key words: multiple sclerosis - disease modifying therapy - pharmacoepidemiology - healthcare

\section{INTRODUCTION}

Multiple sclerosis (MS) is a chronic demyelinating disease of a proposed, but not fully understood, autoimmune origin. It is characterised by either a relapsingremitting course, followed by a secondary progressive course after a variable time period (RRMS), or a primary progressive course (PPMS) (Brownlee et al. 2017). Psychiatric symptoms are common in patients with MS, influencing their quality of life and adherence to treatments (Feinstein et al. 2014.) Among individuals with MS, relative to the general population, lifetime prevalence rates are elevated for major depressive disorder (MDD) (36\%-54\% vs $16.2 \%$ ), bipolar disorder (13\% vs $1 \%-4.5 \%$ ), anxiety disorders (35.7\% vs $28.8 \%$ ), adjustment disorders (22\% vs $0.2 \%-2.3 \%)$, and psychotic disorders $(2 \%-3 \%$ vs $1.8 \%$ ). Suicide may be at least twice as common. Atlhough it is well known that emotional disorders are common among individuals with MS, these disorders are often undetected and inadequately treated (Minden et al. 2014). It is important to recognize thise feature in patients with MS since with effective treatments widely available for several emotional disorders, this component of the burden of MS can be reduced (Goldman Consensus Group 2005). According to the Atlas of MS 2013, the median global prevalence of multiple sclerosis is 33 per 100 000. The highest prevalence is in North America (140 per 100000$)$ and the lowest is in Sub-Saharan
Africa (2.1 per 100000$)$. Prevalence in Europe is estimated to 108 per 100000 (Browne et al. 2014).

Costs and burden of multiple sclerosis are high. According to data collected in Germany during winter 2015/2016 mean total annual costs per patient with Expanded disability status scale (EDSS) (Kurtzke 1984) 0 -3 were $€ 28,200$, $€ 44,000$ per patient with EDSS 46.5 and $€ 62,700$ per patient with EDSS 7-9. Symptoms of multiple sclerosis have great impact on patients' everyday life and work ability: according to a study performed in Germany pain and discomfort were reported by $71 \%$ of patients, mobility problems were present in $59 \%$ of patients and productivity at work was affected by MS in $81 \%$ of patients (Flachenecker et al. 2017).

In the past few decades, an increasing number of drugs intended for decreasing the number of relapses and hopefully improving disease course and outcomes in RRMS have been developed, with a common name: disease modifying therapies (DMTs). The first DMT to be approved internationally for treatment of RRMS was interferon beta during the 1990s (Lublin 2005). During the 2000s two subsequent drugs were approved: glatiramer acetate and natalizumab, a monoclonal antibody reserved for more aggressive cases of disease. In the current decade, there was a surge of new and emerging therapeutic options: teriflunomide, alemtuzumab (another monoclonal antibody), fingolimod and dimethyl fumarate, the latter two being the first oral medications available. There 
are several more drugs currently in the final phases of development (Krieger 2016). Association between psyhiatric symptoms mainly depressed mood and disease-modifying therapies in MS is unclear (Feinstein et al. 2001).

Availability of drugs for treating MS varies a lot among different countries due to their income. According to available data from 2013, fully of partly government funded therapy with interferon $\beta 1 \mathrm{a}$ (IM), interferon $\beta 1 \mathrm{a}(\mathrm{SC})$, interferon $\beta 1 \mathrm{~b}$ and glatiramer acetate was available in $96 \%$ of high income countries, $89 \%$ of upper middle income countries and $45 \%$ of lower middle income countries. In low income countries none of the DMTs funded by government were accessible. Natalizumab and fingolimod were available in the vast majority of countries with high income, but only in $10 \%$ of lower middle income countries (Browne et al. 2014).

The aim of this study was to assess availability and utilization of DMTs in Croatia over the years.

\section{MATERIALS AND METHODS}

The data on DMT usage was provided by the Agency for Medicinal Products and Medical Devices of Croatia
(HALMED). It was supplied in the form of defined daily doses per 1000 inhabitants per day (DDD/1000/day), measured to a precision level of two decimal points. The total annual cost for a particular medication measured in Croatian kuna (HRK) was available, as well as the number of individual packages sold annually. This data represents the total amount sold through distributors, regardless of the route to the end user. Thus, the possibility of data insufficiency was avoided.

The data from 2005 to 2016 was available.

\section{RESULTS}

Consumption of interferon beta was noted in all of the observed years. There were two forms available: 1a and 1-b. In the first few years, consumption of both variants of interferon beta 1-b was similar, but in the last few years it was skewed in favour of interferon beta 1-a (Figure 1). Their combined consumption has markedly increased through the years, beginning with $0.09 \mathrm{DDD} / 1000 /$ day in 2005 , and ending in 0.49 $\mathrm{DDD} / 1000 /$ day in 2016, which represents a more than fivefold increase.

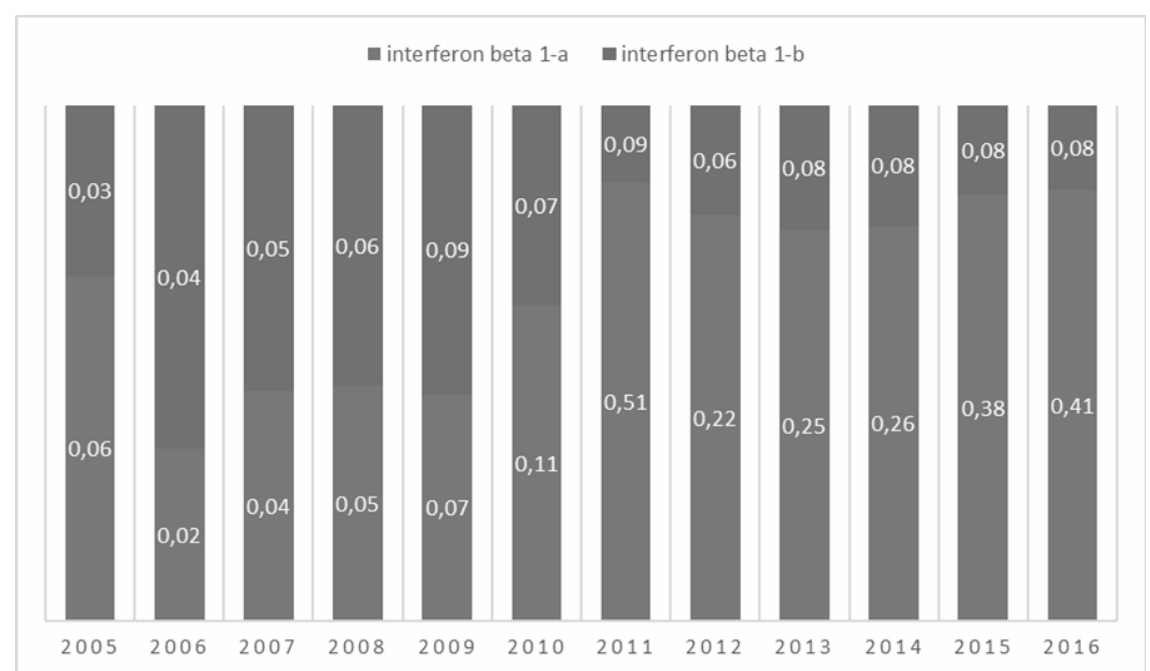

Figure 1. Ratio of consumption of particular forms of interferon beta (in DDD/1000/day)

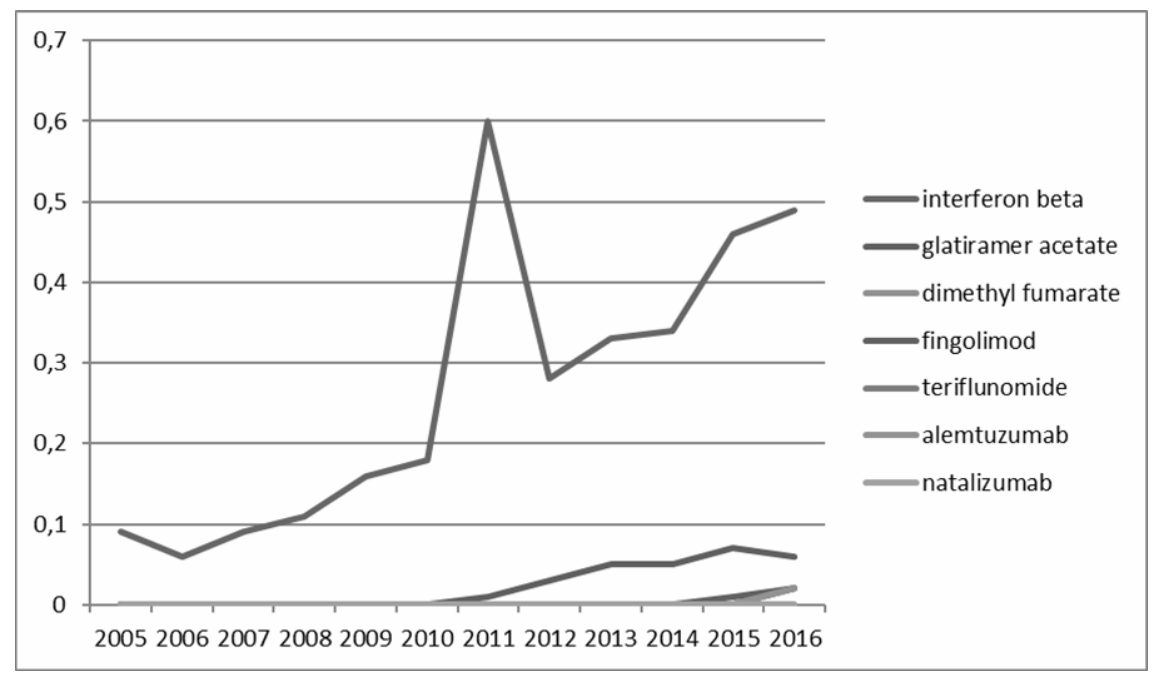

Figure 2. Dynamic of consumption of particular DMTs (in DDD/1000/day) 
There was some consumption of glatiramer acetate in the first half of the observed period, however it was not until 2011 that its consumption began gaining traction. From that year to 2016 the consumption of glatiramer acetate had increased greatly, from 0.01 $\mathrm{DDD} / 1000 /$ day in 2011 to $0.05 \mathrm{DDD} / 1000 /$ day in 2014, and it remained similar in subsequent years. These values are still far below those accomplished by both versions of interferon beta combined, but they are approaching consumption figures of interferon beta 1-b. In the years 2014 to 2016 several new treatment options became available, and promptly gained a reasonable amount of market share. Dimethyl fumarate and teriflunomide as a first line treatment (according to HZZO) have similar consumption figures in 2016 at 0.02 $\mathrm{DDD} / 1000 /$ day, similar to the figures of fingolimod, which is considered a second line treatment.
The consumption of monoclonal antibody natalizumab (another second line treatment) in Croatia was first noted in 2010, and has been increasing steadily since, however the absolute values never rise above the threshold in the DDD/1000/day measurement system. Its consumption figures have been exceeded by another monoclonal antibody, alemtuzumab swiftly after its introduction to the market (Figure 2).

The proportions of DMT usage in 2016 (in the form of DDD/1000/day) is shown in Figure 3.

The annual cost for drugs for which there was consumption in 2016 is distributed unevenly between drugs, with the majority being spent on various versions of interferon beta.

The total annual cost in HRK has increased greatly during the years, from 12.49 million HRK in 2005 to 120.18 million HRK in 2016 (Figure 4).

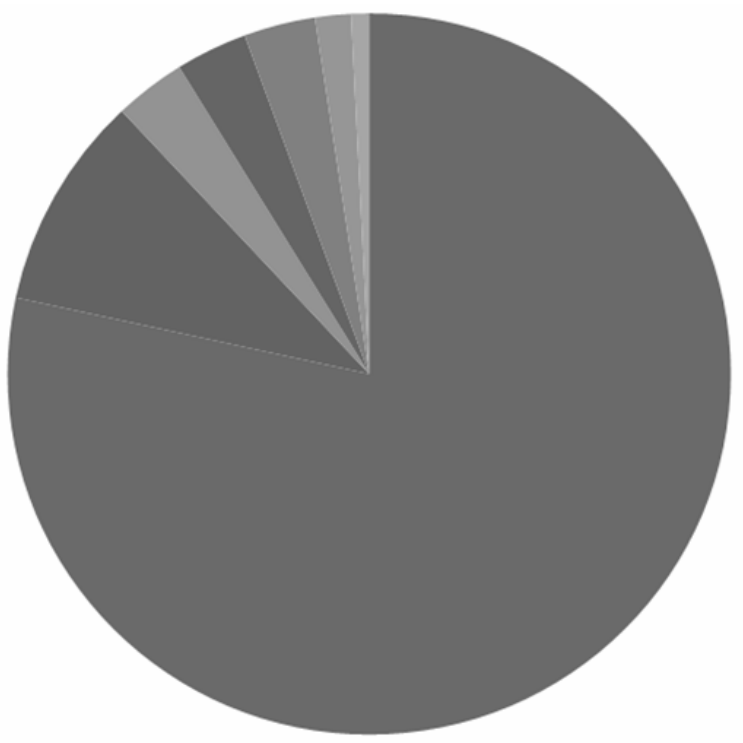

$$
\begin{aligned}
& \text { घ interferon beta } \\
& \text { - glatiramer acetate } \\
& \text { a dimethyl fumarate } \\
& \text { - fingolimod } \\
& \text { n teriflunomide } \\
& \text { alemtuzumab } \\
& \text { natalizumab }
\end{aligned}
$$

Figure 3. Proportion of consumption (measured by DDD/1000/day) of particular DMTs in 2016

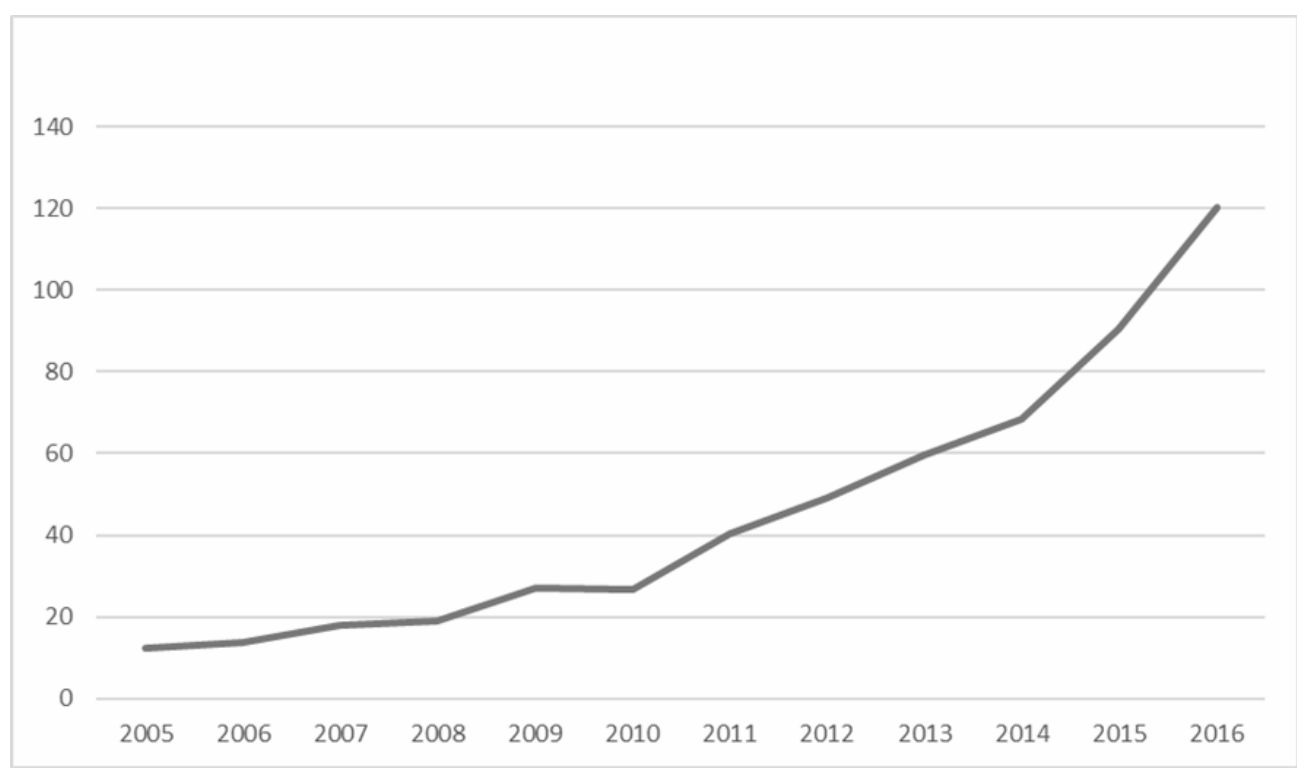

Figure 4. Combined consumption of DMTs through the years (in millions of HRK) 


\section{DISCUSSION}

There have been major changes in consumption of DMTs in the previous years. Before 2010 the only disease modifying therapeutic option in Croatia was interferon beta, and it has since become available in several formulations. Lately, several drugs of similar efficacy have emerged, and are now available through the healthcare system. The first of those to become available, glatiramer acetate, has since gained the largest market share. Consumption of dimethyl fumarate has been increasing since it has become available, partly probably due to it offering greater ease of use for the patient because of its oral administration method.

In Croatia, those are the medications that the guidelines of the Croatian health insurance fund (HZZO) recommend as the first line of treatment. It is possible to prescribe those medications (with reimbursement from the fund) only after the following criteria for disease duration and activity have been met: 2 or more confirmed and treated relapses in the past two years, and that more than one year has elapsed from the diagnosis (HZZO 2017). These criteria are more stringent than those in most European countries, which contributes to the delay in starting the patients on DMTs, as well as reducing the total number of patients receiving them.

Until recently, the patients were only eligible for the second line of treatment (alemtuzumab, fingolimod, natalizumab) after inadequate response to the first line of treatment and after fulfilling the criteria for cessation of said therapy (either 3 or more relapses in one year or an increase in EDSS by 1 point in conjunction with relapses over a 12 month period or an increase in EDSS by 1 point without relapses over a 6 month period (HZZO 2017), so the use of the aforementioned DMTs was sporadic, with natalizumab gaining the biggest market share, due to it being the first highly efficient DMT to become available for reimbursed treatment through the HZZO. Recently, the guidelines for prescription of alemtuzumab have been altered, so that it can now be prescribed as a first line of treatment in patients with highly active multiple sclerosis (two or more disabling relapses, defined as an increase in EDSS of $\geq 2$ in one year) (HZZO 2017). This turn of events will probably cause the consumption of alemtuzumab to increase greatly in the future.

The rate of increase of DMT consumption is lagging behind some developed countries, such as Australia and Germany, where similar growth patterns have been observed several years ahead of those demonstrated here. For example, in Australia during the period between December 2011 and November 2012 the total number of fingolimod scripts was 27,884 . In the following few years growth of consumption of fingolimod was recorded and during the period between December 2013 and November 2014 the number of scripts of fingolimod increased to 53,310 (DUSC 2015). In comparison, fingolimod became available in Croatia for the first time in 2013. In Germany in $200518.6 \%$ of patients with multiple sclerosis were treated with glatiramer acetate (Höer et al. 2014). In comparison, in 2005 glatiramer acetate was still not available in Croatia, but in 2011 and 2012, there was a large and sudden increase of utilization of glatiramer acetate in Croatia. Fortunately, most of the new therapeutic options are now available for prescription in Croatia and are broadly used.

Psychiatric comorbidites are common among patients with MS, but they are often left unrecognized and inappropriately treated (Minden et al. 2014). Therefore it would be interesting and worthwhile to investigate utilization of psychiatric medications among patients with MS in Croatia. Unfortunately, data on this subject is not available at the moment and further research on this topic should be conducted in the future.

The estimated number of patients with MS in Croatia is around 6,000 individuals (HZJZ 2017), and one can estimate with some certainty from the DDD/1000/day figures shown earlier that around a third of all MS patients in 2016 were treated with a DMT. We cannot compare those estimations to the data from other countries, as this kind of data is scarce and unreliable, but we can assume that the proportion is smaller than that in those other countries, judging by their more immediate availability of DMTs.

\section{CONCLUSION}

The consumption of drugs intended to treat multiple sclerosis in Croatia has increased greatly, especially in the last few years of the observed period, but is still lagging behind the levels present in some other developed countries. This is partially due to differences in which the particular healthcare systems handle prescription eligibility (if the costs are to be reimbursed by the state), especially given that the annual cost per patient is still too great for the Croatian patient to endure financially without aid from the healthcare system. In the following years, it is important to monitor the consumption trends in light of the introduction of subsequent, potentially more effective medications on the market.

\section{Contribution of individual authors:}

Sanja Tomasović: study concept and design, acquisition of data, analysis and interpretation of data, drafting/revising the manuscript, critical revision of the manuscript for important intellectual content, study supervision.

Jelena Košćak Lukač: analysis and interpretation of data, drafting the manuscript, design of the figures.

Josip Sremec: analysis and interpretation of data, drafting the manuscript, design of the figures.

Nataša Klepac: analysis and interpretation of data, critical revision of the manuscript for important intellectual content.

Pero Draganić: acquisiton of dana and analysis of data.

Ivan Bielen: critical revision of the manuscript for important intellectual content, study supervision. 


\section{Acknowledgements: None.}

\section{Conflict of interest: None to declare.}

\section{References}

1. Browne P, Chandraratna D, Angood C, Tremlett H, Baker C, Taylor BV et al.: Atlas of Multiple Sclerosis 2013: A growing global problem with widespread inequity. Neurology 2014; 83:1022-4

2. Brownlee WJ, Hardy TA, Fazekas F, Miller DH: Diagnosis of multiple sclerosis: progress and challenges. Lancet; 389:1336-1346

3. Drug utilisation sub-committee (DUSC): Multiple sclerosis: predicted versus actual analysis; 2015;

http://www.pbs.gov.au/industry/listing/participants/publicrelease-docs/10-2015/multiple-sclerosis-dusc-prd-201510-final.pdf. Accessed 1.10.2017

4. Feinstein A, Magalhaes S, Richard JF, Audet B, Moore C: The link between multiple sclerosis and depression. Nat Rev Neurol 2014; 10:507-17

5. Feinstein A, Feinstein K: Depression associated with multiple sclerosis: looking beyond diagnosis to symptom expression. J Affect Disord 2001; 66:193-8

6. Goldman Consensus Group: The Goldman Consensus statement on depression in multiple sclerosis. Mult Scler $2005 ; 11: 328-37$
7. Hrvatski zavod za javno zdravstvo: Nacionalni dan oboljelih od multiple skleroze; 13.7.2017; Accessed 1.10.2017; https://www.hzjz.hr/dogadaj/nacionalni-dan-oboljelih-odmultiple-skleroze/

8. Hrvatski zavod za zdravstveno osiguranje: Osnovna lista lijekova; 25.7.2017; Accessed 1.10.2017,

http://www.hzzo.hr/zdravstveni-sustav-rh/trazilica-zalijekove-s-vazecih-listal

9. Krieger SC: Multiple Sclerosis and Other Demyelinating Diseases: Continuum (Minneap Minn) 2016; 22:723-9

10. Kurtzke JF: Disability rating scales in multiple sclerosis. Ann N Y Acad Sci 1984; 436:347-60

11. Flachenecker P, Kobelt G, Berg J, Capsa D, Gannedahl M; European Multiple Sclerosis Platform: New insights into the burden and costs of multiple sclerosis in Europe: Results for Germany. Mult Scler 2017; (suppl 2):78-90

12. Höer A, Schiffhorst G, Zimmermann A, Fischaleck J, Gehrmann L, Ahrens $H$ et al: Multiple sclerosis in Germany: data analysis of administrative prevalence and healthcare delivery in the statutory health system. BMC Health Serv Res 2014; 14:381

13. Lublin F: History of modern multiple sclerosis therapy. $J$ Neurol 2005; 252(Suppl 3):iii3-iii9

14. Minden SL, Feinstein A, Kalb RC, Miller D, Mohr DC, Patten SB, et al.: Evidence-based guideline: assessment and management of psychiatric disorders in individuals with MS: report of the Guideline Development Subcommittee of the American Academy of Neurology. Neurology 2014; 82:174-81

Correspondence:

Sanja Tomasović, $M D, P h D$

Department of Neurology, University Hospital "Sveti Duh"

Sveti Duh 64, 10000 Zagreb, Croatia

E-mail: stomasovic98@gmail.com 